\title{
Prediction Model for Spontaneous Combustion of Coal around Boreholes Using Bedding Gas Drainage
}

\author{
Youxin Zhao $\mathbb{D}^{1,2}$ Qingjie Qi, ${ }^{1,2,3,4}$ and Xinlei Jia ${ }^{3,4}$ \\ ${ }^{1}$ Department of the Emergency Research Institute, China Coal Research Institute CCRI, Beijing 100013, China \\ ${ }^{2}$ State Key Laboratory of Efficient Mining and Clean Utilization of Coal Resources, Beijing 100013, China \\ ${ }^{3}$ School of Safety Science and Engineering, Liaoning Technical University, Fuxin 123000, Liaoning, China \\ ${ }^{4}$ Key Laboratory of Mine Thermodynamic Disasters and Control of Ministry of Education, Fuxin 123000, Liaoning, China \\ Correspondence should be addressed to Youxin Zhao; 553663095@qq.com
}

Received 24 February 2021; Revised 21 April 2021; Accepted 8 May 2021; Published 15 May 2021

Academic Editor: Feng Du

Copyright $\odot 2021$ Youxin Zhao et al. This is an open access article distributed under the Creative Commons Attribution License, which permits unrestricted use, distribution, and reproduction in any medium, provided the original work is properly cited.

\begin{abstract}
To accurately and reliably predict the time of spontaneous combustion of fractured coal around a borehole induced by gas drainage along the seam, this study performed an orthogonal test taking the No. 10 Coal Mine of Pingdingshan as the research object, in terms of the suction negative pressure and coal seam buried depth. COMSOL Multiphysics was used to model the orthogonal test results, and a multielement statistical analysis of four factors and their relationships with the spontaneous combustion of coal around the borehole and a single-factor analysis in line with the site conditions were performed on the modeling results through multiple regression. The results showed a nonlinear regression relationship between the sealing hole length, sealing hole depth, negative pressure, and coal seam depth and the spontaneous combustion of the coal around the gas drainage borehole; the prediction regression model is significant. Taking the field gas drainage in the No. 10 Coal Mine of Pingdingshan as an example, the relationship between the time of spontaneous combustion of gas drainage and the drainage pressure follows a power of two. When the drainage negative pressure is less than $45 \mathrm{kPa}$, the coal around the borehole is more likely to undergo spontaneous combustion with increasing pressure, and the sealing hole length has a positive linear correlation with the time of spontaneous combustion of the coal around the borehole. When the sealing hole length is $23 \mathrm{~m}$, the time of spontaneous combustion of the coal around the gas drainage hole is $>500$ days, and the coal around the borehole does not easily undergo spontaneous combustion. When the sealing depth is $15 \mathrm{~m}$, the time of spontaneous combustion of the coal around the gas drainage hole is 76 days, which is most likely to cause spontaneous combustion.
\end{abstract}

\section{Introduction}

Coal is a basic form of energy in China, and gas leakage has been the main factor threatening the safety of coal production with increasing mining depth. Bedding gas drainage is an important method for solving the problem of gas leakage at the mining face. The mainly used methods to improve the gas drainage efficiency include enlarging the borehole diameter $[1,2]$, increasing the gas drainage pressure [3], densifying the boreholes [4], increasing the extraction time of gas drainage, and increasing the permeability of the coal seam [5-7]. However, from the perspective of fire prevention, the methods used to improve the gas drainage efficiency may increase the risk of spontaneous combustion of the coal around the borehole. This is mainly due to the following reasons: increasing the gas drainage diameter and coal seam permeability lead to a more fully developed fractured coal around the borehole, thus widening the air leakage channel. Increasing the gas extraction pressure increases the amount of oxygen entering the borehole. Prolonging the extraction time of gas drainage borehole increases the oxidation time for coal spontaneous combustion. The spontaneous combustion of the surrounding coal due to gas drainage boreholes seriously affects the smooth progress of projects and poses a safety risk to miners working in the coal mining face. Taking the No. 10 
Mine of Pingdingshan as an example, 1,947 prepumped boreholes for gas drainage were constructed along the 24130 mining face in 2019, among which 425 boreholes were found to have a CO concentration of over $300 \mathrm{ppm}$, accounting for $21.8 \%$ of all gas drainage boreholes. To prevent the spontaneous combustion of the coal around these boreholes due to gas drainage, an early prediction of the spontaneous combustion time of the coal around the bedding gas drainage borehole can play a significant role in the prevention and control of such disasters.

Accurately predicting the temperature [8] and time of spontaneous combustion [9] is key for an effective prevention and control of spontaneous combustions in mines. Currently, most scholars predicted the spontaneous combustion time mainly in the gob. For example, Wei et al. [10] optimized the index gas of spontaneous combustion and divided the spontaneous combustion area into "three zones" with the $\mathrm{O}_{2}$ concentration as the indicator. Gao et al. [11] proposed a support vector regression method and established a spontaneous combustion model using the particle swarm optimization algorithm. Deng et al. [12, 13] proposed a fuzzy least-squares spherical support vector machine algorithm to solve a quadratic programming problem in FLHSSVM and established a prediction model for coal spontaneous combustion. Meng et al. [14-16] organically combined rough set and support vector machine algorithms to establish a spontaneous combustion prediction model for the gob based on the rough set and support vector machine. Zhou et al. [17] used a BP neural network to predict the reignition of coal mine fire areas after opening and established a prediction model. Wu et al. [18] analyzed the essential characteristics of coal spontaneous combustion from the perspective of nonlinear theory and established a prediction model for the spontaneous combustion using a BP-based neural network, which was verified on site in Chaili Coal Mine of Zaozhuang Mining Group Company, Shandong Province. Wang et al. [19] proposed a method combining grey and Markov models to predict the spontaneous combustion of coal. Genc [20] systematically introduced the prediction of spontaneous combustion liability in coal mines, and the relationships between the intrinsic and extrinsic properties of coal and coalshale were established. The intrinsic and extrinsic factors of the coal and coal-shale could be used to effectively investigate the cause of spontaneous combustion incidents and predict them in the future. The above-mentioned domestic and foreign scholars have conducted several experiments and numerical simulation studies on the prediction of coal spontaneous combustion in goafs; however, few have studied the spontaneous combustion of coal around the borehole induced by gas drainage, which severely restricts the efficient and safe use of gas drainage.

In summary, several studies have been conducted on the time of spontaneous combustion in the gob and coal seam [21-24]; however, studies on the spontaneous combustion induced by gas drainage are lacking. To solve the drilling time prediction model for bedding-induced combustion, field measurement and theoretical analysis are conducted to study the factors influencing coal spontaneous combustion around the borehole. The orthogonal test method is used to construct a multiparameter gas drainage mathematical model of the spontaneous combustion of coal around the borehole. Based on the numerical simulation results, a stepwise regression method is used to establish a prediction model for the spontaneous combustion time of the coal around the borehole. Based on the actual gas drainage situation of Pingdingshan No. 10 Mine, we study and analyze the relationships between the drainage negative pressure, plugging length, plugging depth, and drainage time and help select the optimum drainage and sealing parameters. The hole parameters provide a theoretical basis for preventing the spontaneous combustion of coal around gas drainage boreholes.

\section{Engineering Background}

The No. 10 Mine of Pingdingshan is located in the northeast of Pingdingshan City, approximately $6 \mathrm{~km}$ from the downtown center. The mine field is approximately $6.0 \mathrm{~km}$ long in the north-south direction and $2.0-4.7 \mathrm{~km}$ wide in the east-west direction. The operation of the No. 10 Mine was commenced in August 1958, with an annual production capacity of 1.2 million tons and a service life of 68 years. The mining method includes advancing the mining area, backward section, up and down of the mountain layout of the long wall roof, and full caving. The mining method is fully mechanized mining. The main mining coal seam is the No. 15 coal seam, and the second group coal seam is mainly distributed in the 24070, 24100, and 24130 mining faces with buried depths of approximately 635,981 , and $1239 \mathrm{~m}$, respectively. The gas pressure is in the range of $0.1-1.85 \mathrm{MPa}$, the gas content is in the range of $2.15-20.0374 \mathrm{~m}^{3} / \mathrm{t}$, the permeability of the coal seam is $0.0019 \mathrm{mD}$, and the attenuation coefficient is $0.068 \mathrm{D}^{-1}$.

\section{Analysis of the Factors Influencing the Spontaneous Combustion of Coal around Borehole}

The spontaneous combustion of coal around the borehole induced by gas drainage is affected not only by geological factors, mining technology, coal quality, and ventilation mode, but also by the gas drainage technology and hole sealing parameters $[25,26]$. In addition, there are variations in the mining areas, mining faces in different environments, drainage technology, and drainage parameters, and the development degree of spontaneous combustion around drilling holes can be different. Gas drainage-induced spontaneous combustion of the surrounding coal is a catastrophic behavior of complex nonlinear dynamic systems in the process of time and space evolution and is one of the main factors affecting coal mine safety production.

Although gas drainage-induced spontaneous combustion of coal is affected by internal factors, external factors can be decisive in that they determine whether the coal around the gas drainage borehole will undergo a spontaneous combustion. In the gas drainage process, an excessively high negative pressure can reduce the gas concentration in the borehole, increase the energy loss, and easily result in a 
spontaneous combustion of the coal around the borehole. If the negative pressure is too low, the gas drainage concentration in the borehole is reduced, the drainage period is increased, and the probability of spontaneous combustion around the borehole is increased. A too short sealing hole length can cause the gas in the roadway to enter the drainage borehole, reduce the amount of gas drainage, and cause the surrounding coal to undergo spontaneous combustion. If the sealing hole length is too long, it increases the difficulty of sealing the hole in terms of the time required and the complexity of the parameters involved, which reduces the work efficiency. When the hole sealing depth is too large, the plugging section exceeds the peak stress value, and some coal seams are around the plugging section, resulting in a blind area in the gas drainage process. When the sealing length is too small and the sealing section of the drainage hole is located within the plastic zone of the roadway, the surrounding coal body is broken to a higher degree. In the drainage process, the gas concentration is easily diluted by the gas flowing into the drainage hole through the plastic zone, and it is easy to cause a spontaneous combustion of the coal body around the plugging section.

3.1. Temperature of Coal Seam. Based on the above analysis, to study the influence of gas drainage on the spontaneous combustion of coal around the borehole, the CO concentration was detected in three boreholes adjacent to the 24070 , 24100, and 24130 working faces of Pingdingshan No. 10 Mine. The detection results were then averaged to obtain the relationship between the average $\mathrm{CO}$ concentration in the borehole and the gas drainage time, as shown in Figure 1.

The spontaneous combustion of coal around the borehole can be reflected by monitoring the $\mathrm{CO}$ concentration. Figure 1 shows that there is almost no $\mathrm{CO}$ in the gas drainage borehole in the early stages of gas drainage. As the drainage progresses, the $\mathrm{CO}$ concentration in the borehole shows a trend of gradual increase at first and then a sharp increase. Regarding the general trend, there is a gradual increase in the CO concentration at the 24070, 24100, and 24130 mining faces within 40 days of applying gas drainage. According to Qi et al. [27], the deeper the buried depth into the coal seam, the higher the temperature. The main reason is that the three groups of test boreholes are located at different working faces, and their buried depths are 635, 918, and $1239 \mathrm{~m}$. Based on the difference in the CO concentrations in the boreholes of different coal seams, we find that the coal seam temperature affects the ignition time of the spontaneous combustion of coal. The index selection is a factor influencing the spontaneous combustion time.

3.2. Hole Sealing Parameters. To study the influence of the sealing parameters on the spontaneous combustion of coal around the borehole, eight experimental boreholes with different sealing parameters were designed in the 24130 working face. The specific sealing parameters of the $1 \#$ and $2 \#$ boreholes are $(15,6)$, those of the $3 \#$ and $4 \#$ boreholes are $(15,8)$, those of the $5 \#$ and $6 \#$ boreholes are $(23,8)$, and those of the $7 \#$ and $8 \#$ boreholes are $(23,10)$. Here, $(15,8)$ means that the hole sealing depth is $15 \mathrm{~m}$ and that the hole sealing length is $8 \mathrm{~m}$. The CO concentration in the gas drainage borehole was detected within 40 days; Figure 2 shows the relationship between the drainage time and the $\mathrm{CO}$ concentration in the borehole.

As shown in Figure 2, when the sealing parameters of boreholes $1 \#$ and $2 \#$ are $(15,6)$, the CO concentration in the boreholes is significantly higher than that in the other three groups of boreholes. The sealing parameters of boreholes $3 \#$ and $4 \#$ are $(15,8)$, and the sealing depth is the same. Evidently, the longer the sealing length, the lower the CO concentration in the gas drainage borehole. The sealing parameters of the $5 \#$ and $6 \#$ drilling holes are $(23,8)$, and the maximum CO concentration is $200 \mathrm{ppm}$, which is far lower than that of $(15,8)$, indicating that the sealing length is the same and that the deeper the sealing depth, the lower the CO concentration in the drilling holes. When the sealing parameters of holes $7 \#$ and $8 \#$ are $(23,13)$, there is almost no $\mathrm{CO}$ in the holes within 40 days. In summary, it can be concluded that the sealing depth and length of the gas drainage borehole affect the spontaneous combustion of the coal around the borehole and that these parameters can be used as indicators of the natural combustion time of coal.

3.3. Suction Negative Pressure. Typically, if the negative pressure applied during coal seam drainage is constant, to reflect the different drainage from the coal body around the drilling holes under negative pressure changes over time, we conducted a simulation based on COMSOL software on the 24130 mining face under a hole sealing depth of $18 \mathrm{~m}$, sealing hole length of $10 \mathrm{~m}$, and drainage pressures of $15,20,23,28$, and $35 \mathrm{kPa}$ to study the spontaneous combustion situation around the borehole. Figure 3 shows the relationship between the maximum coal temperature around the negativepressure gas drainage borehole and the gas drainage time. As shown, when the negative pressure of drainage is in the range of $15-35 \mathrm{kPa}$, with the continuation of the gas drainage time, the $\mathrm{CO}$ concentration in the fractured coal body around the borehole increases. At the same time, the negative pressure of gas drainage increases, and the highest temperature of the coal body around the borehole increases. The growth rate also increases; hence, the negative pressure of drainage is another important factor affecting the spontaneous combustion of coal around gas drainage boreholes.

\section{Orthogonal Experimental Design}

Based on the different negative pressures of field pumping, sealing parameters, and buried depth of the mining face, orthogonal tests at four levels were set for the four factors. Table 1 lists the specific levels and causal values. The results of 16 groups of experiments were obtained by SPSS 25.0, as listed in Table 2.

The 16 groups of orthogonal experimental results listed in the table were simulated using COMSOL Multiphysics software; Figure 4 shows some of the results.

Relevant experiments were carried out based on the orthogonal experimental design, and 16 groups of 


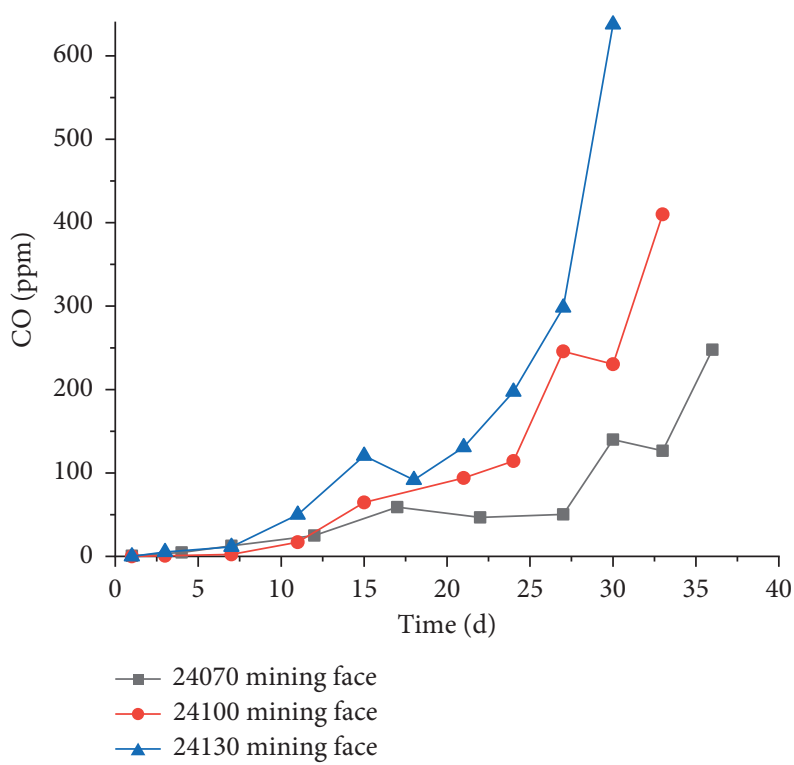

FIGURE 1: Variation in CO concentration with time in the different mining faces.

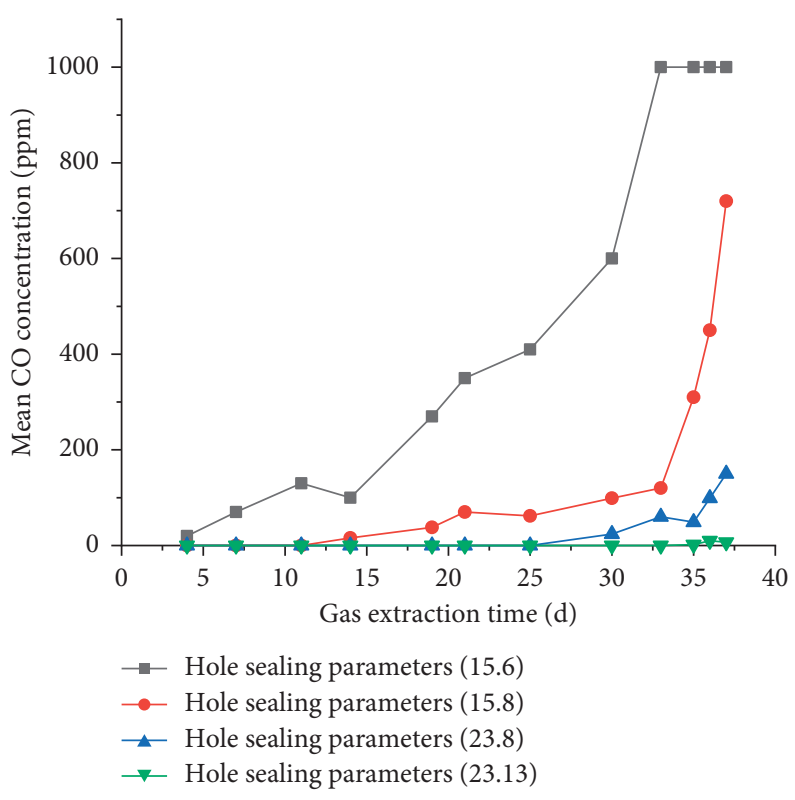

FIgURE 2: Change curve of average CO concentration in a single borehole under different sealing parameters.

experimental data were simulated to obtain the time required for the temperature of the coal around the borehole to reach $70^{\circ} \mathrm{C}$. Because of the number of experiments, cloud maps could not be attached individually. Figure 2 shows the simulation results corresponding to numbers $2,4,6,8,10$, and 12. Figure 4 shows that the location of the spontaneous combustion of coal is 1-2 $\mathrm{m}$ from the outer end of the sealing hole and that different sealing parameters, drainage negative pressure, and coal seam temperature affect the time of spontaneous combustion of coal around the gas drainage borehole. Based on the orthogonal experimental design, the simulation results of the spontaneous combustion time of coal body induced by gas drainage with different numbers are shown in Table 2.

\section{Prediction of Spontaneous Combustion Time of Coal Induced by Gas Drainage}

5.1. Stepwise Regression Analysis. In practice, the regression equation expressing the functional relationship between the variables should be accurately established. If there are a large number of variables in the regression equation or if there is a certain degree of similarity between the variables, this will decrease the degree of freedom of the regression equation 


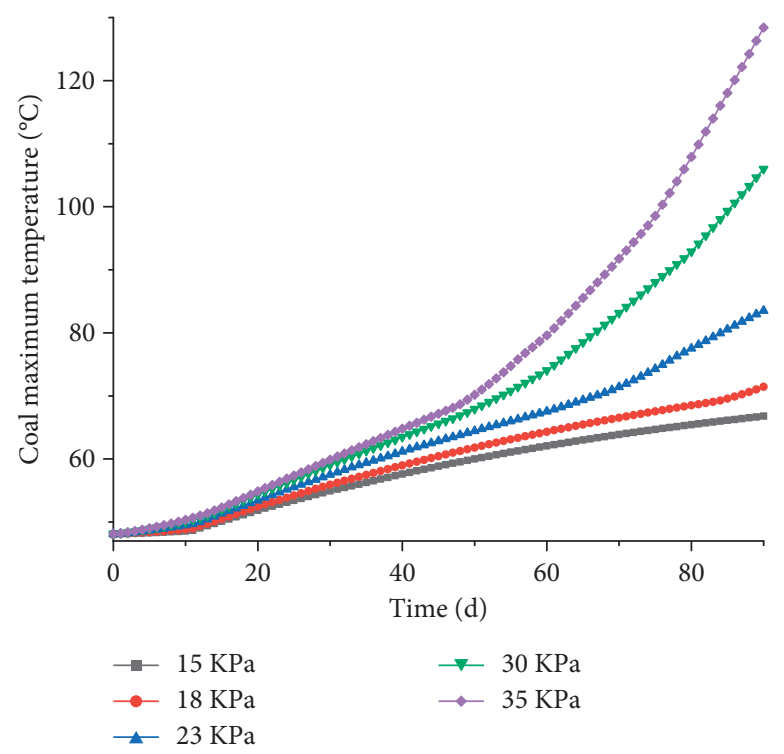

Figure 3: Relationship between maximum temperature of coal around the drilling hole and the drainage time under different negative pressure conditions.

TABLE 1: Parameters and their values.

\begin{tabular}{lcccc}
\hline Serial number & Negative pressure drainage $\left(P_{1} / \mathrm{kPa}\right)$ & Sealing length $\left(F_{c} / \mathrm{m}\right)$ & Sealing depth $\left(F_{s} / \mathrm{m}\right)$ & Seam temperature $(\mathrm{K})$ \\
\hline 1 & 18 & 6 & 15 & 308.15 \\
2 & 23 & 8 & 18 & 312.15 \\
3 & 30 & 10 & 20 & 316.15 \\
4 & 35 & 13 & 23 & 321.15 \\
\hline
\end{tabular}

TABLE 2: Spontaneous combustion time.

\begin{tabular}{|c|c|c|c|c|c|}
\hline Serial number & Negative pressure drainage $(\mathrm{kPa})$ & Sealing length $(\mathrm{m})$ & Sealing depth $(\mathrm{m})$ & Seam temperature $(\mathrm{K})$ & Time $(\mathrm{d})$ \\
\hline 1 & 23 & 10 & 23 & 321.15 & 250 \\
\hline 2 & 23 & 8 & 18 & 308.15 & 109 \\
\hline 3 & 35 & 8 & 20 & 316.15 & 66 \\
\hline 4 & 35 & 13 & 23 & 308.15 & 551 \\
\hline 5 & 35 & 6 & 18 & 321.15 & 39 \\
\hline 6 & 18 & 8 & 23 & 312.15 & 401 \\
\hline 7 & 35 & 10 & 15 & 312.15 & 76.5 \\
\hline 8 & 18 & 6 & 15 & 308.15 & 83 \\
\hline 9 & 30 & 10 & 20 & 308.15 & 145 \\
\hline 10 & 30 & 13 & 18 & 312.15 & 151 \\
\hline 11 & 23 & 13 & 15 & 316.15 & 98 \\
\hline 12 & 23 & 6 & 20 & 312.15 & 82 \\
\hline 13 & 18 & 13 & 20 & 321.15 & 594 \\
\hline 14 & 30 & 8 & 15 & 321.15 & 60 \\
\hline 15 & 30 & 6 & 23 & 316.15 & 69 \\
\hline 16 & 18 & 10 & 18 & 316.15 & 164 \\
\hline
\end{tabular}

due to estimate increase and have a certain influence on the accuracy of the regression equation. Therefore, to establish an optimal regression equation, it is necessary to filter variables that have significant influence on the independent variables.
The regression methods include forward, backward, and step-by-step regression methods. Each method has its own advantages and disadvantages; however, the step-by-step regression method is the most convenient and can be used to quickly conduct a regression analysis of the variables. With 


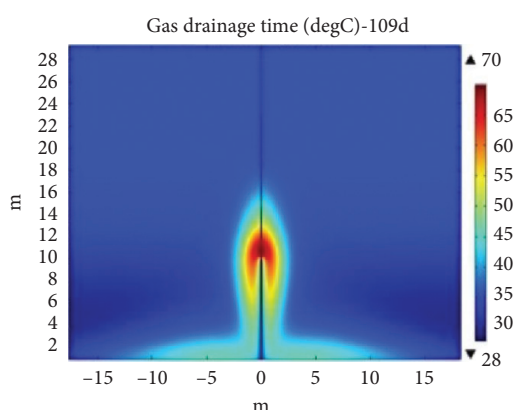

(a)

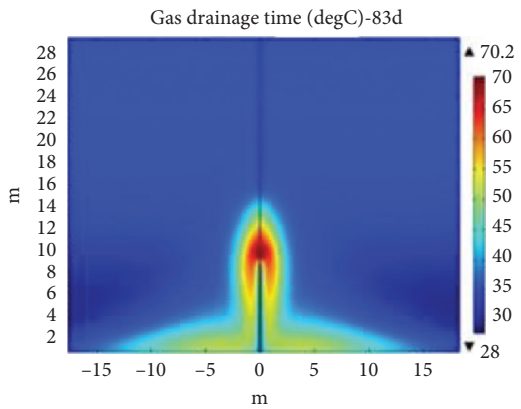

(d)

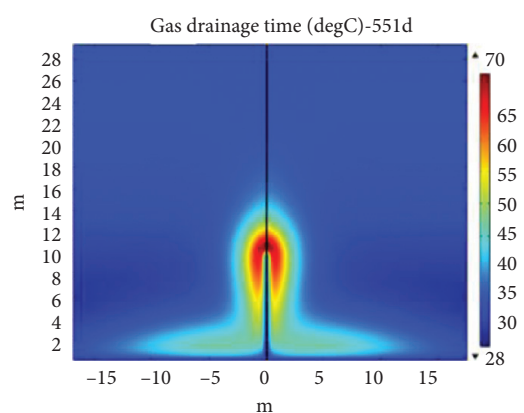

(b)

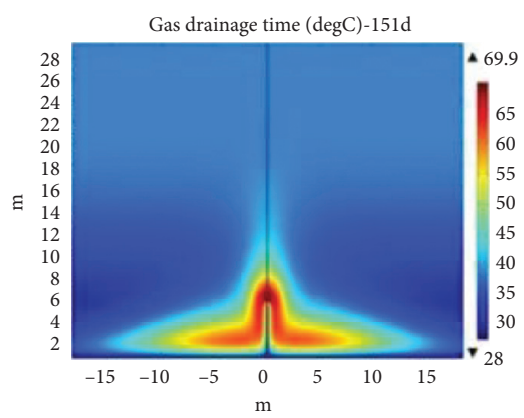

(e)

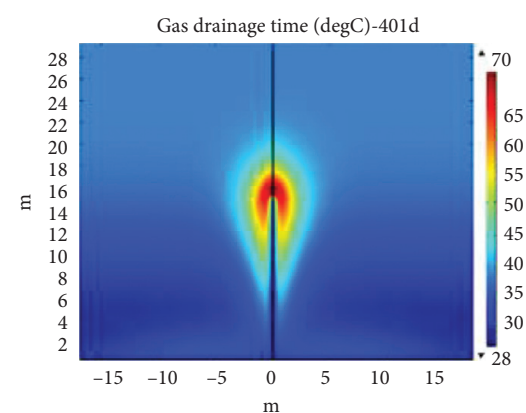

(c)

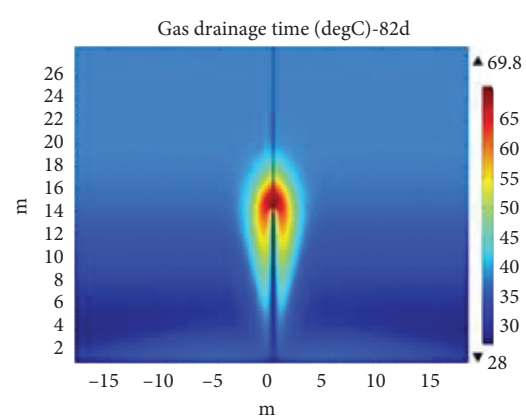

(f)

FIgURE 4: Simulation results under different scenarios. (a) 2. (b) 4. (c) 6. (d) 8. (e) 10. (f) 12.

the step-by-step regression method applied to construct an optimal regression equation, we can obtain the optimal solution.

\subsubsection{Standardization of Observed Variables. If} $\left(x_{\alpha 1}, x_{\alpha 2}, \ldots, x_{\alpha p} ; y_{\alpha}\right), \alpha=1,2, \ldots, n$ is a group of observed data $\left(x_{1}, x_{2}, \ldots, x_{p}, y\right)$ values of the variables, the standardized transformation of the observed value is

$$
z_{\alpha j}=\frac{x_{\alpha i}-\overline{x_{j}}}{\sigma_{j}}, \quad \alpha=1,2, \ldots, n, j=1,2, \ldots, m,
$$

where $\overline{x_{j}}=1 / n \sum_{\alpha=1}^{n} x_{\alpha i}, \sigma_{j}^{2}=\sum_{\alpha=1}^{n}\left(x_{\alpha j}-\overline{x_{j}}\right)^{2}$.

A standardized regression equation for $y=x_{m}$ and $x_{1}$, $x_{2} \ldots, x_{m-1}$ can be established. If the relationship between the variables is nonlinear, the normalized data can be further processed using the least-squares principle. Based on the research content of this paper, four observed variables form a new data sequence: $z_{i}, z_{1}^{2}, z_{i} z_{j},(i<j)$, respectively. $z_{1}, z_{2}$, $z_{3}, z_{4}, z_{1}^{2}, z_{2}^{2}, z_{3}^{2}, z_{4}^{2}, z_{1} z_{2}, z_{1} z_{3}, z_{1} z_{4}, z_{2} z_{3}, z_{2} z_{4}, z_{3} z_{4}$. Thus, the regression result is a nonlinear equation:

$$
\widehat{y}=b_{0}+\sum_{i=1}^{4} b_{i} z_{i}+\sum_{i=1}^{4} b_{i i} z_{i}^{2}+\sum_{i<j}^{4} z_{i} z_{j} .
$$

5.1.2. Regression Process. The maximum partial regression $R 2$ is selected to construct the $F$ statistic, and the operation is repeated to select the maximum partial regression $R 2$. If the $F$ value of the current construction is greater than that of the remaining variables, the variables will be introduced. Otherwise, there will be no significant variables, and the regression is terminated.

\subsection{Time Stepwise Regression Analysis of Coal Spontaneous Combustion Induced by Gas Drainage}

5.2.1. Data Standardization. As listed in Tables 1 and 2, the data normalization conversion method was used to standardize the four influencing factors, namely the suction negative pressure $P 1$, drilling hole sealing length $F c$, drilling hole sealing depth FS, and ground temperature $T c$, to establish 
a functional relationship with the spontaneous ignition time of the pumping hole. The calculation process is as follows:

$$
\begin{aligned}
\overline{F c} & =9.25, \\
\overline{F c} & =9.25, \\
\overline{F s} & =19.0, \\
\overline{T c} & =314.40, \\
\overline{Y t} & =188.9688, \\
\sigma_{P} & =6.71, \\
\sigma_{F c} & =2.67, \\
\sigma_{F s} & =3.01, \\
\sigma_{T c} & =4.97, \\
\sigma_{Y t} & =184.46 \\
Z_{P} & =\frac{P_{i}-\bar{P}}{\sigma_{P}}, \\
Z_{F c} & =\frac{F c_{i}-\overline{F c}}{\sigma_{F c}}, \\
Z_{F s} & =\frac{F s_{i}-\overline{F s}}{\sigma_{F s}}, \\
Z_{T c} & =\frac{T c_{i}-\overline{T c}}{\sigma_{T c}}, \\
Z_{Y t} & =\frac{Y t_{i}-\overline{Y t}}{\sigma_{Y t}} .
\end{aligned}
$$

The new variables obtained from the normalization of the variables are denoted by $Z_{Y t}, Z_{P}, Z_{F t}, Z_{F S}$, and $Z_{T c}$.

The set of data obtained by the nonlinear data transformation of the new variable is $Z_{P}^{2}, Z_{F c}^{2}, Z_{F s}^{2}, Z_{T c}^{2}, Z_{P} Z_{F c}$, $Z_{P} Z_{F s}, Z_{P} Z_{T c}, Z_{F c} Z_{F s}, Z_{F s} Z_{T c}$. Therefore, all the variables are combined into a new set of variables: $Z_{Y t}, Z_{P}, Z_{F t}, Z_{F S}, Z_{T \mathrm{c}}$, $Z_{P}^{2}, Z_{F c}^{2}, Z_{F s}^{2}, Z_{T c}^{2}, Z_{P} Z_{F c}, Z_{P} Z_{F s}, Z_{P} Z_{T c}, Z_{F c} Z_{F s}, Z_{F s} Z_{T c}$.

5.2.2. Introduction and Deletion of Variables. The variables were introduced and eliminated according to the principle of the $\mathrm{F}$ test where $F \leq 0.1$ was directly introduced, and $F \geq 0.11$ was excluded. After eight steps, seven variables in Table 3 were introduced, and 1 variable was removed.

5.2.3. Establishment of Coal Spontaneous Combustion Model Induced by Gas Drainage. In Step 8, the results of each parameter are listed in Table 4 . From the eight-step regression calculation in the stepwise regression process, with the increase in the steps and the introduction of the corresponding significant variables, the $R 2$ of the model gradually increased, and the error gradually decreased. Finally, an eight-step model was established through eightstep calculation, and its $R 2$ was 0.912 , which meets the requirements of engineering and theory, indicating that the established model is reasonable.

5.2.4. Standardized Residual Analysis. In the process of model building and stepwise regression, a standardized residual analysis was carried out by default using the SPSS software, and the histogram and normal probability diagrams of the standardized residual were drawn. As shown in Figure 5(a), Std.Dev $=0.775, N=16$; Figure 5(b) shows that the cumulative probability of the observation is around the expected probability, further proving that the process is reasonable and that the model is correct.

5.2.5. Coefficient for Solving Equations. The eight-step regression process is also where the variables are introduced and removed, where the first correlation test of the variables is conducted, and where the coefficients are generated. Finally, the coefficients of the relevant variables are obtained from Model 8. Given the length constraints, only the coefficients of Step 8 are listed in Table 5.

As listed in Table 5, the Sig. values of almost all the variables and constant terms introduced into Model 10 are 0 , indicating a strong and significant correlation, which proves the rationality of the model and the correctness of solving the coefficient of the relevant variables.

$$
\begin{aligned}
Z_{Y t}= & -0.797+0.558 Z_{P}^{2}+0.549 Z_{F s}-0.367 Z_{P} \\
& +0.494 Z_{F c}+0.292 Z_{T c}^{2}-0.225 Z_{F s} Z_{T c} .
\end{aligned}
$$

The variables in (4) are restored to the original variables, and the simple (f) function in MATLAB is called to obtain the simplest command program, as expressed in

$$
\begin{aligned}
Y t= & 34.1 F c+905 F s-131 P_{1}-1317 T c \\
& +0.228 P_{1}^{2}+2.18 T c^{2}-2.77 F s T_{c}+199672 .
\end{aligned}
$$

Fitting equation (5) shows that the spontaneous ignition time of the gas pumping borehole is jointly affected by four factors. The sealing length and depth of the holes have a linear positive correlation with the spontaneous ignition time of the drilling holes, whereas the negative pressure of pumping and ground temperature have a quadratic negative correlation.

\section{Single-Factor Analysis of the Prediction Model for Spontaneous Combustion of Coal around Borehole}

To study the influence of a single factor on the drilling spontaneous ignition time, a control variable method is adopted to control three factors, and only the influence of the single factor on the drilling spontaneous ignition time is studied. The coal seam ground temperature of the 24130 mining face in the field is generally $321.15 \mathrm{~K}$. Therefore, we only analyzed and studied the influences of the suction 
TABLE 3: Entered/removed variables.

\begin{tabular}{lcr}
\hline Model & Input variable & Removed variable \\
\hline 1 & $Z_{P} Z_{T c}$ & Step (input $F \leq .1$, excluding $F \geq .11$ ) \\
2 & $Z_{P}{ }^{2}$ & Step (input $F \leq .1$, excluding $F \geq .11$ ) \\
3 & $Z_{F s}$ & Step (input $F \leq .1$, excluding $F \geq .11$ ) \\
4 & $Z_{P}$ & Step (input $F \leq .1$, excluding $F \geq .11$ ) \\
5 & $Z_{F c}$ & Step (input $F \leq .1$, excluding $F \geq .11$ ) \\
6 & $Z_{P} Z_{T c}$ & Step (input $F \leq .1$, excluding $F \geq .11$ ) \\
7 & $Z_{T c}^{2}$ & Step (input $F \leq .1$, excluding $F \geq .11$ ) \\
8 & $Z_{F s} Z_{T c}$ & Step (input $F \leq .1$, excluding $F \geq .11$ ) \\
\hline
\end{tabular}

TABLE 4: Model variances.

\begin{tabular}{|c|c|c|c|c|c|c|c|}
\hline \multirow{2}{*}{ Model } & \multirow{2}{*}{$R$} & \multirow{2}{*}{$R^{2}$} & \multirow{2}{*}{ Adjusted $R^{2}$} & \multirow{2}{*}{ Error in standard estimation } & \multicolumn{3}{|c|}{ Change in the statistical metrics } \\
\hline & & & & & $R^{2}$ variation & $F$ variation & Degrees of freedom 1 \\
\hline 1 & $0.634^{\mathrm{a}}$ & 0.402 & 0.359 & 0.80064328 & 0.402 & 9.400 & 1 \\
\hline 2 & $0.741^{\mathrm{b}}$ & 0.549 & 0.479 & 0.72164473 & 0.147 & 4.233 & 1 \\
\hline 3 & $0.817^{\mathrm{c}}$ & 0.667 & 0.584 & 0.64475177 & 0.119 & 4.286 & 1 \\
\hline 4 & $0.867^{\mathrm{d}}$ & 0.751 & 0.660 & 0.58278835 & 0.083 & 3.687 & 1 \\
\hline 5 & $0.904^{\mathrm{e}}$ & 0.817 & 0.726 & 0.52346855 & 0.066 & 3.634 & 1 \\
\hline 6 & $0.904^{\mathrm{f}}$ & 0.817 & 0.750 & 0.49992426 & -0.001 & 0.033 & 1 \\
\hline 7 & $0.934^{\mathrm{g}}$ & 0.872 & 0.808 & 0.43806416 & 0.055 & 4.326 & 1 \\
\hline 8 & $0.955^{\mathrm{h}}$ & 0.912 & 0.853 & 0.38307345 & 0.040 & 4.077 & 1 \\
\hline
\end{tabular}

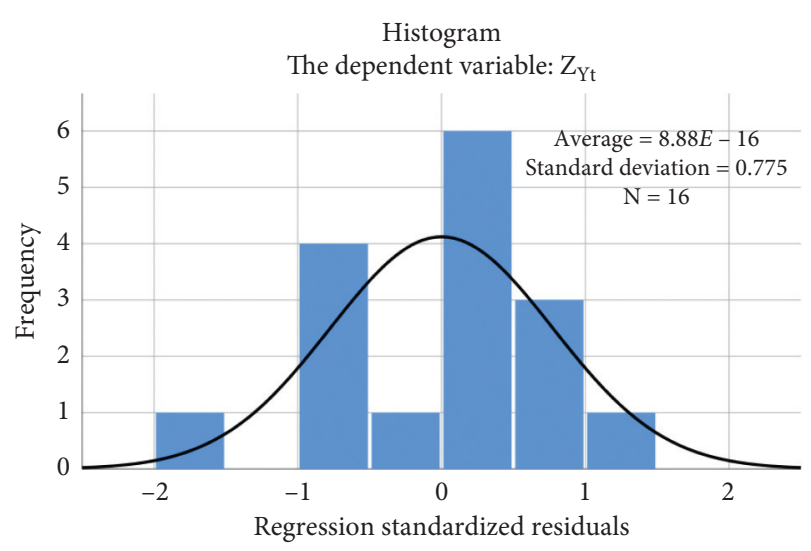

(a)

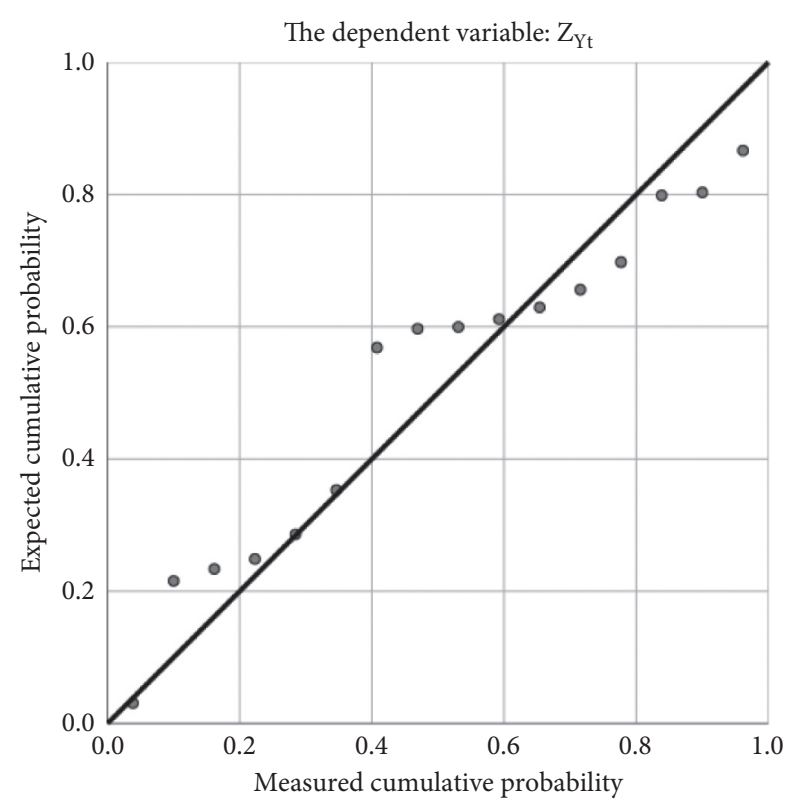

(b)

Figure 5: Histogram and P-P diagram of simulation results. (a) Histogram. (b) P-P figure.

TABLE 5: Coefficients of the relevant variables.

\begin{tabular}{|c|c|c|c|c|c|c|}
\hline & \multirow{2}{*}{ Model } & \multicolumn{2}{|c|}{ Unnormalized coefficient } & \multirow{2}{*}{$\begin{array}{c}\text { Normalized coefficient } \\
\text { Beta }\end{array}$} & \multirow{2}{*}{$t$} & \multirow{2}{*}{ Significance } \\
\hline & & $B$ & Standard error & & & \\
\hline \multirow{7}{*}{8} & (Constant) & -0.797 & 0.202 & & -3.953 & 0.003 \\
\hline & $Z_{P}^{2}$ & 0.558 & 0.144 & 0.383 & 3.876 & 0.004 \\
\hline & $Z_{F s}$ & 0.549 & 0.099 & 0.549 & 5.555 & 0.000 \\
\hline & $Z_{P 1}$ & -0.367 & 0.106 & -0.367 & -3.457 & 0.007 \\
\hline & $Z_{F c}$ & 0.494 & 0.101 & 0.494 & 4.898 & 0.001 \\
\hline & $Z_{T c}^{2}$ & 0.292 & 0.123 & 0.235 & 2.378 & 0.041 \\
\hline & $Z_{F s} Z_{T c}$ & -0.225 & 0.112 & -0.218 & -2.019 & 0.074 \\
\hline
\end{tabular}


negative pressure, hole sealing length, and hole sealing depth on the ignition time of the drilling holes.

6.1. Influence Analysis of Suction Negative Pressure. To analyze the influence of suction negative pressure $P_{1}$ on the spontaneous ignition time $Y t$ of the borehole, the sealing hole length, sealing hole depth, and ground temperature were fixed to study the influence rule. Based on the field drilling pumping conditions, the hole sealing length of the 24130 mining face is $8 \mathrm{~m}$, the hole sealing depth is $15 \mathrm{~m}$, and the ground temperature is $321.15 \mathrm{~K}$. Substituting the known conditions into (6), we obtain

$$
Y t=0.228 P_{1}^{2}-20.52 P_{1}+496.7 \text {. }
$$

With (6), the relationship curve between the negative pressure $P_{1}$ of pumping and $Y t$ of spontaneous ignition time of the borehole is drawn. Between $18 \mathrm{kPa}$ and $45 \mathrm{kPa}$, with the increase in the negative pressure of pumping, the coal around the borehole is more prone to spontaneous combustion. When the negative pressure of pumping is $18 \mathrm{kPa}$, $Y t$ is 201 days. When the suction negative pressure is $45 \mathrm{kPa}$, the shortest time of spontaneous ignition is 35 days. Because of the pressure loss of the pumping pipeline, the suction negative pressure of each drilling hole is different, and the spontaneous ignition time of each drilling hole also changes. The actual suction negative pressure of field drilling is between $18 \mathrm{kPa}$ and $25 \mathrm{kPa}$. For a hole sealing length of $8 \mathrm{~m}$, hole sealing depth of $15 \mathrm{~m}$, and ground temperature of $321.15 \mathrm{~K}$, spontaneous combustion begins to occur during drilling in 126 days, as shown in Figure 6.

6.2. Influence Analysis of Hole Sealing Length. To analyze the influence of hole sealing length $F c$ on the spontaneous ignition time $Y t$, the negative pressure of pumping, hole sealing depth, and ground temperature were fixed to study the influence rule. Based on the sealing parameters determined by the simulation analysis and field tests, the negative pressure of pumping was set to $23 \mathrm{kPa}$, the sealing depth was set to $23 \mathrm{~m}$, and the ground temperature was set to $321.15 \mathrm{~K}$. Substituting the known conditions into (7), we obtain

$$
Y t=34.1 F c-129 \text {. }
$$

With (7), the relationship between the sealing hole length and drilling spontaneous ignition time is plotted. The sealing hole length has a positive linear correlation with the drilling spontaneous ignition time. When the sealing hole length is $6 \mathrm{~m}, Y t$ is 75 days, and natural ignition phenomenon is most likely to occur in the coal around the drilling hole. When the hole sealing length is $23 \mathrm{~m}$, the hole is a full hole deep sealing hole, and the natural ignition time of the coal around the hole is $>500$ days, and the natural ignition phenomenon will not occur in the hole, as shown in Figure 7.

6.3. Influence Analysis of Hole Sealing Depth. To analyze the influence of sealing depth on the spontaneous ignition time of the drilling holes, the suction negative pressure, sealing hole length, and ground temperature were fixed to study the

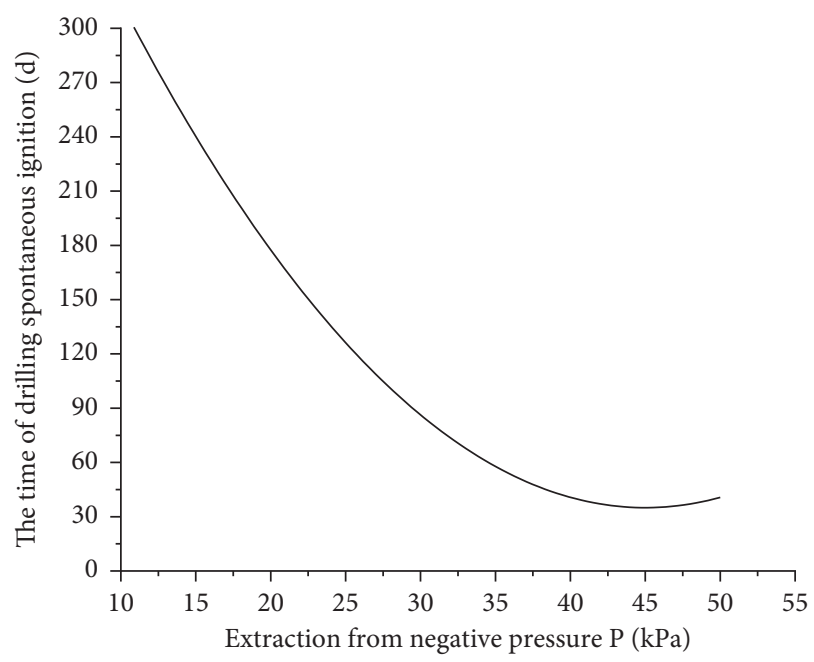

FIGURE 6: Influence of pumping negative pressure on the natural ignition time of borehole.

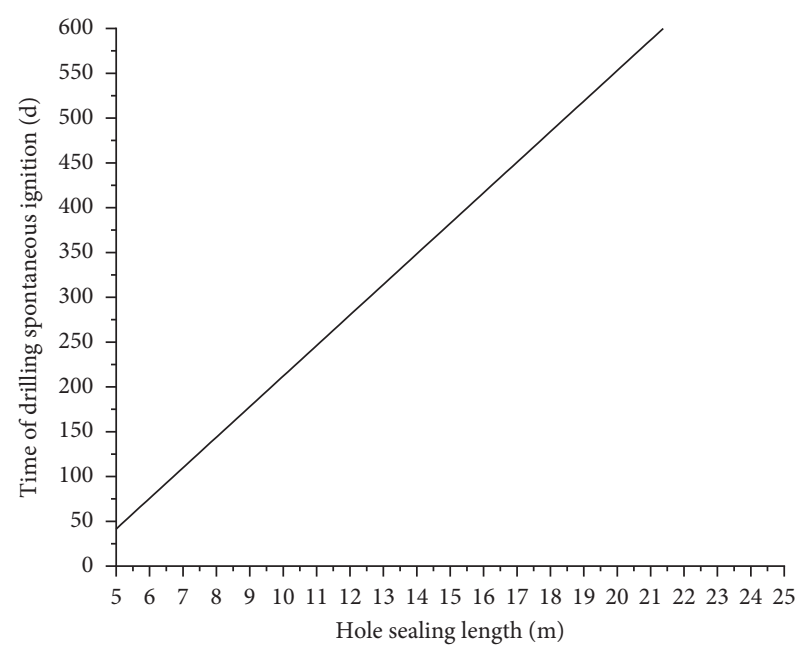

FIGURE 7: Influence of sealing length on the natural ignition time of borehole.

influence rule. Based on the sealing parameters determined by the simulation analysis and field tests, the negative pressure of pumping was $-23 \mathrm{kPa}$, the sealing length was $10 \mathrm{~m}$, and the ground temperature was $321.15 \mathrm{~K}$. Substituting the known conditions into (8), we obtain

$$
Y t=25.4145 F s-305 .
$$

Using (8), the relationship between the sealing hole depth and the drilling spontaneous ignition time is plotted. The sealing hole depth has a positive linear correlation with the drilling spontaneous ignition time. When the sealing hole depth is $15 \mathrm{~m}, Y t$ is 76 days, and spontaneous ignition phenomenon is most likely to occur during drilling. When the hole sealing depth is $30 \mathrm{~m}$, the drilling spontaneous ignition time is more than 450 days, and the drilling spontaneous ignition phenomenon cannot easily occur, as shown in Figure 8. 


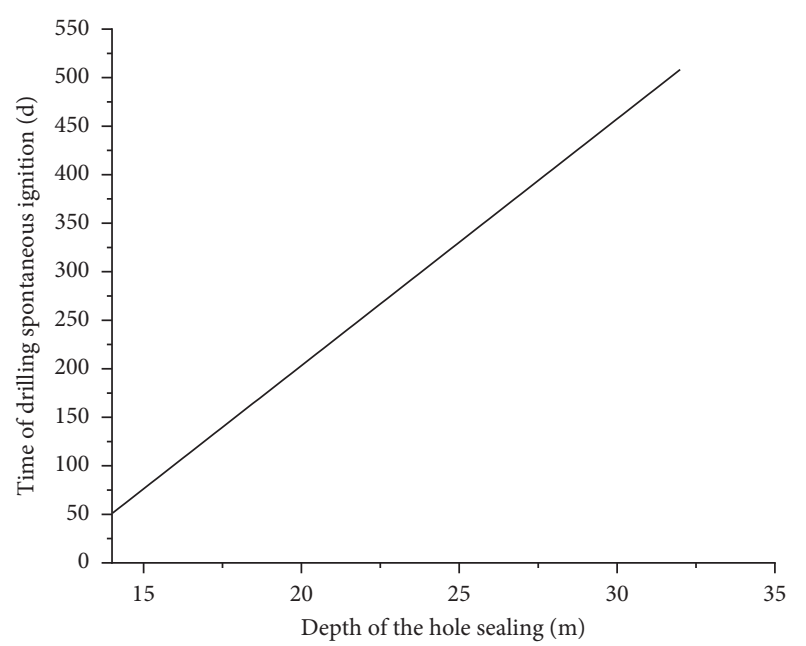

FIGURE 8: Influence of sealing depth on natural ignition time of borehole.

\section{Conclusion}

(1) In view of the lack of current methods for determining the spontaneous combustion time of broken coal around the borehole induced by bedding gas drainage, a multiple stepwise regression method based on a combination of orthogonal test and numerical simulation was proposed to predict the time pattern of the spontaneous combustion of coal around the borehole.

(2) We plotted the nonlinear regression relationship between four factors, namely the sealing hole length, sealing hole depth, suction negative pressure, and coal seam depth, and the spontaneous combustion time of coal around the borehole fissure. The sealing length and depth of the holes were found to have a linear positive correlation with the spontaneous ignition time of the drilling holes, whereas the negative pressure of pumping and ground temperature had a quadratic negative correlation.

(3) Taking the actual gas drainage situation at the 24130 mining face of the No. 10 Mine of Pingdingshan as an example, we derived an equation relating the gas drainage negative pressure with the natural combustion time of the borehole: $Y t=0.228 P_{1}^{2}+20.52 P_{1}+496.7$. The relationship between the natural combustion time of gas drainage and drainage pressure follows a power of 2 . The equation relating the sealing hole length and the spontaneous ignition time of the drilling hole is $Y t=34.1 F c-129$. The equation relating to the sealing hole depth with the drilling spontaneous ignition time is $Y t=25.414 F s-305$. The sealing hole depth has a positive linear correlation with the drilling spontaneous ignition time.

\section{Data Availability}

The data used to support the findings of this study are included within the article.

\section{Conflicts of Interest}

There are no conflicts of interest regarding the publication of this paper.

\section{Acknowledgments}

The authors would like to thank Rodrigo Cabanero for its linguistic assistance during the preparation of this manuscript. This work was supported by the National Key R\&D Plan Key Special Funding Project (grant no. 2018YFC0807900), the China Coal Technology \& Engineering Group Co., Ltd. (2019-2-ZD003), the National Natural Science Foundation Youth Project of China (grant no. 51804161), the National Natural Science Foundation of China (grant no. 52074156), and China Postdoctoral Science Foundation (2020M680490).

\section{References}

[1] F. Hao, L. Sun, and F. Zhao, "Borehole diameter shrinkage rule considering rheological properties and its effect on gas drainage," PLoS One, vol. 15, no. 9, Article ID e0239016, 2020.

[2] Y. Wang, W. Yan, Z. Ren, Z. Yan, Z. Liu, and H. Zhang, "Investigation of large-diameter borehole for enhancing permeability and gas extraction in soft coal seam," Geofluids, vol. 2020, no. 6, 13 pages, Article ID 6618590, 2020.

[3] S. N. Zhou, "Theory and application of gas flow in coal sea," Journal of China Coal Society, vol. 2, no. 1, pp. 24-37, 1965.

[4] L. Yuan, "Strategic thinking of simultaneous exploitation of coal and gas in deep mining," Journal of China Coal Society, vol. 41, no. 1, pp. 1-6, 2016.

[5] D. D. Xu, Y. Q. Tao, Z. T. Zhou et al., "Study of the law of hydraulically punched boreholes on effective gas drainage radius under different coal outputs," Shock and Vibration, vol. 2020, Article ID 8858091, 12 pages, 2020.

[6] W. W. Ma, J. T. Li, and W. X. Liang, "Experimental study and application of directional subdivision hydraulic fracturing and permeability improvement device," Coal Science and Technology, vol. 47, no. 5, pp. 132-138, 2019.

[7] D. M. Zhang, X. Bai, G. Z. Yin et al., "Research and application on technology of increased permeability by liquid CO2 phase change directional jet fracturing in low-permeability coal seam," Journal of China Coal Society, vol. 43, no. 7, pp. 1938-1950, 2018.

[8] J. Deng, C. K. Lei, K. Cao et al., "Random forest method for predicting coal spontaneous combustion in gob," Journal of China Coal Society, vol. 43, no. 10, pp. 2800-2808, 2018.

[9] L. Wei, Y. P. Qin, C. Shi et al., "Dynamic evolution of spontaneous combustion of coal in longwall gobs during mining-stopped period," Process Safety and Environmental Protection, vol. 132, 2019.

[10] D. Wei, C. Du, B. Lei et al., "Prediction and prevention of spontaneous combustion of coal from gobs in workface: a case 
study," Case Studies in Thermal Engineering, vol. 21, Article ID 100668, 2020.

[11] Y. Gao, M. G. Qin, and G. J. Li, "Analysis on prediction of residual coal spontaneous combustion in doaf based on Support vector machine," Coal Science and Technology, vol. 38, no. 2, pp. 50-54, 2010.

[12] J. Deng, C. K. Lei, K. Cao et al., "Support vector regression approach for predicting coal spontaneous combustion," Journal of Xi'an University of Scienece and Technology, vol. 38, no. 2, pp. 175-180, 2018.

[13] J. Deng, S. L. Zhou, L. Ma et al., "Research on prediction method of coal spontaneous combustion degree based on PCA-PSOSVM," Mining Safety and Environmental Protection, vol. 43, no. 5, pp. 27-31, 2016.

[14] Q. Meng, H. Q. Wang, Y. S. Wang et al., "Predicting limit parameters of coal self-ignition based on support vector machine," Journal of China Coal Society, vol. 34, no. 11, pp. 1489-1493, 2009.

[15] L. L. Zhao, G. H. Wen, and L. B. Shao, "PCA-Ada Boost model for predicting coal spontaneous combustion in caving zone with imbalanced data," China Safety Science Journal, vol. 28, no. 3, pp. 74-78, 2018.

[16] Q. Meng, Y. S. Wang, and T. Zhou, "Prediction of spontaneous combustion in caving zone based on rough set and support vector machine," Journal of China Coal Society, vol. 35, no. 12, pp. 2100-2104, 2010.

[17] F. B. Zhou and J. H. Li, "Prediction model for reignition of fire zone after unsealing based on BP neural networks," Journal of Mining and Safety Engineering, vol. 27, no. 4, pp. 494-498, 2010.

[18] J. M. Wu and J. F. Wang, "Anon-linear prediction of coal selfignition based on neural network," China Safety Science Journal, vol. 5, pp. 15-17, 2004.

[19] L. Wang, S. J. Wu, and C. Q. Li, "Coal spontaneous combustion prediction based on grey-markov model," Computer Simulitation, vol. 31, no. 11, pp. 416-420, 2014.

[20] B. Genc, "Spontaneous combustion liability of coal and coalshale: a review of prediction methods," International Journal of Coal Science and Technology, vol. 6, no. 2, pp. 151-168, 2019.

[21] H. Wang, B. Tan, Z. Shao, Y. Guo, Z. Zhang, and C. Xu, "Influence of different content of FeS2 on spontaneous combustion characteristics of coal," Fuel, vol. 288, Article ID 119582, 2021.

[22] H. Wang, X. Fang, F. Du et al., "Three-dimensional distribution and oxidation degree analysis of coal gangue dump fire area: a case study," Science of The Total Environment, vol. 772, Article ID 145606, 2021.

[23] F. Du, K. Wang, X. Zhang, C. Xin, L. Shu, and G. Wang, "Experimental study of coal-gas outburst: insights from coalrock structure, gas pressure and adsorptivity," Natural Resources Research, vol. 29, no. 4, pp. 2481-2493, 2020.

[24] Q. J. Qi, Y. X. Zhao, X. H. Li et al., "Prediction model of CO emission volume from gob," Coal Science and Technology, vol. 46, no. 2, pp. 182-186, 2018.

[25] H. Wang, X. Fang, Y. Li, Z. Zheng, and J. Shen, "Research and application of the underground fire detection technology based on multi-dimensional data fusion," Tunnelling and Underground Space Technology, vol. 109, Article ID 103753, 2021.

[26] F. Du and K. Wang, "Unstable failure of gas-bearing coal-rock combination bodies: insights from physical experiments and numerical simulations," Process Safety and Environmental Protection, vol. 129, pp. 264-279, 2019.
[27] Q. J. Qi, Y. X. Zhao, X. L. Jia et al., "Cause analysis and prevention of spontaneous combustion in deep coal seam drilling," China Safety Science Journal, vol. 29, pp. 37-42, 2019. 